\title{
Biotinidase Deficiency: A Cause of Subacute Necrotizing Encephalomyelopathy (Leigh Syndrome). Report of a Case with Lethal Outcome $^{1}$
}

\author{
E. REGUlA BAUMGARTNER, TERTTU M. SUORMALA, HUGO WICK, ALPHONSE PROBST, \\ URSULA BLAUENSTEIN, CLAUDE BACHMANN, AND MARKUS VEST
}

University Children's Hospital, Basel, [E.R.B., T.M.S., H.W.], Department of Pathology, University of Basel, [A.P.], Children's Hospital Bruderholz, [U.B., M.V.], and, Clinical Chemistry, University of Lausanne, [C.B.], Lausanne, Switzerland

\begin{abstract}
An unusual clinical course of a patient with biotinidase deficiency, causing Leigh syndrome, is reported. Laryngeal stridor was the major presenting symptom followed by progressive neurologic deterioration and death at the age of 21.5 mo. Absence of skin and hair abnormalities as well as of organic aciduria delayed the correct diagnosis. Necropsy revealed subacute necrotizing encephalopathy (Leigh syndrome). Carboxylase activities (propionyl CoA carboxylase, 3-methylcrotonyl-CoA carboxylase, pyruvate carboxylase) measured in lymphocytes 1 day before death were decreased to $10 \%$ of normal values. Propionyl-CoA carboxylase was shown to be the only stable carboxylase in human postmortem tissue; in our patient it was moderately decreased in postmortem liver ( $29 \%$ of control) and kidney $(42 \%)$, but severely decreased in brain (3\%). These findings might explain the severity of neurological symptoms in the absence of marked organic aciduria. They indicate that in biotinidase deficiency the CNS may become biotin depleted earlier and more severely than other organs. Biotinidase deficiency should be included in the differential diagnosis of Leigh syndrome and of unexplained respiratory problems. (Pediatr Res 26:260266, 1989)
\end{abstract}

\section{Abbreviations}

ACC, acetyl-CoA carboxylase

GLDH, glutamate dehydrogenase

MCC, 3-methylcrotonyl-CoA carboxylase

PC, pyruvate carboxylase

PCC, propionyl-CoA carboxylase

SNE, subacute necrotizing encephalomyelopathy

DTT, dithiothreitol

Biotinidase deficiency was discovered by Wolf et al. in 1983 (1) as the primary enzyme defect in most patients with late-onset multiple carboxylase deficiency (2). Patients with this autosomal recessive disorder are unable to cleave covalently bound biotin

Received February 7, 1989; accepted April 11, 1989.

Correspondence Regula Baumgartner, M.D., Children's Hospital Basel, Metabolic Unit, Römergasse 8, CH-4005 Basel, Switzerland.

Supported by Grant 3.9412.0.85 from the Swiss National Foundation.

Presented as poster and abstract (P45) at the 24th Annual Symposium of the Society for the Study of Inborn Errors of Metabolism, September 1986, Amersfoort, The Netherlands. from biocytin and biotinyl-peptides, i.e. degradation products of carboxylases. Therefore they are unable to recycle biotin or to use bound biotin from the diet (3). They ultimately become biotin-deficient, which results in deficient activity of the four biotin-dependent carboxylases (PCC, MCC, PC, and ACC) (4). In consequence ketosis, lactic acidosis and typical organic aciduria may occur.

The clinical symptoms usually develop during infancy or early childhood and are very variable, as recently reviewed (5). The disease most often presents with neurologic symptoms, particularly seizures, and muscular hypotonia. In addition, skin rash, alopecia, ataxia, hearing loss, respiratory abnormalities, and developmental delay are often observed. If present, metabolic acidosis and characteristic organic aciduria are the key features for diagnosis, but both may present relatively late or not at all. The great variability in clinical presentation and time of onset has often delayed diagnosis. The disorder can be treated easily and effectively with pharmacologic doses of biotin $(2,5,6)$. However, early diagnosis is crucial, because delayed biotin substitution may result in irreversible neurologic damage or even death (7).

We here report a patient with an unusual clinical course leading to death at the age of 21.5 mo. Diagnosis of biotinidase deficiency was established only shortly before death, when organic aciduria became detectable. Necropsy findings and biochemical studies are described. Our observation is the first report of biotinidase deficiency as a cause of histopathologically verified Leigh syndrome.

\section{CASE REPORT}

T.A. was born at term after an uneventful pregnancy and delivery, the first child of unrelated parents. Birth wt $3630 \mathrm{~g}$, length $49 \mathrm{~cm}$. She was breast-fed for $2.5 \mathrm{mo}$. Apart from recurrent episodes of vomiting she developed normally and could walk almost unaided at $11 \mathrm{mo}$. From age 2.5 to $9 \mathrm{mo}$ she was receiving $\sim 4 \mu \mathrm{g}$ of free biotin daily (commercially added to the cereal of the cow's milk formula and to a modified milk preparation (HN 25, Milupa)). After 9 mo of age, when the diet was changed to solids and normal milk, she received no added biotin. Vomiting ceased.

At 11 mo she was admitted to the Children's Hospital Bruderholz with acute febrile laryngotracheitis. She was intubated and mechanically ventilated for $5 \mathrm{~d}$. No neurologic abnormalities were noted at this stage. Ht and wt were in the 25-50th centile, head circumference in the 10 th centile. Subsequently recurrent inspiratory and less prominent expiratory stridor occurred so that bronchoscopy was performed at $13 \mathrm{mo}$. It revealed a large 
and floppy epiglottis. Because of increasing symptoms bronchoscopy was repeated at 14 mo. Paradoxical movements of the vocal cords, as seen in central neurogenic disturbance, were noted. A tracheal cannula was inserted by tracheostomy.

After the age of 12 mo neurologic abnormalities developed, fluctuating considerably: muscular hypotonia, truncal ataxia, athetoid movements, and myocloni. Later there was progressive loss of motor functions, dysphagia, and marked salivation. An EEG at 12 mo was normal except for the absence of sleep spindles. Two mo later in addition isolated multifocal steep gradients and sharp waves during sleep were found. The following investigations were normal: CT scan of the brain, auditory evoked potentials, nerve conduction velocity and electromyogram, electroretinogram, fundoscopy, and nerve and skin histology. However, visually evoked potentials showed prolonged latencies.

Routine laboratory investigations of blood, urine, and cerebrospinal fluid, including ammonia, as well as serologic studies were normal. Metabolic screening revealed slightly elevated levels of plasma lactate $(2.5-2.9 \mathrm{mmol} / \mathrm{L}$; normal up to 1.8$)$ and alanine $(520 \mu \mathrm{mol} / \mathrm{L}$; normal $254 \pm 78)$. Plasma and urine concentrations of all other amino acids were in the normal range. Organic acid analysis of the urine showed a three- to fourfold increase of 3 -hydroxy-isovalerate on two different occasions $(0.23$ and 0.21 $\mathrm{mol} / \mathrm{mol}$ creatinine; normal up to 0.05 ) but no other abnormal metabolites. Capillary blood $\mathrm{pH}$ varied between 7.38 and 7.56 with low $\mathrm{PCO}_{2}(14.0-29.5 \mathrm{~mm} \mathrm{Hg})$, base excess from +0.7 to $-10.6 \mathrm{mEq} / \mathrm{L}$. The anion gap was elevated to $25.4 \mathrm{mmol} / \mathrm{L}$.

At 16 mo anticonvulsive treatment with clonazepam and phenobarbital was instituted. Growth and wt gain remained satisfactory whereas the head circumference dropped to the $3 \mathrm{rd}$ centile $(44.7 \mathrm{~cm})$.

Between 18 and 21 mo of age further developmental regression was noted with progressive muscular hypotonia, severe ataxia, focal cloni, myocloni, and an increasingly dull facial expression with an open mouth and drooling. Episodes of somnolence, apathy, and hyperventilation became more frequent, At $21 \mathrm{mo}$ a CT brain scan demonstrated symmetrical hypodense areas adjacent to the third ventricle, in the hypothalamus, the upper part of the pons and in the lamina quadrigemina. Blood lactate levels were elevated to $3.6 \mathrm{mmol} / \mathrm{L}$. The tracheal cannula was closed and because no respiratory problems developed it was removed $1 \mathrm{wk}$ later. The next day, at home, she vomited and later became apathetic. An episode of hyperventilation was followed by gasping respiration. On emergency admission the patient was comatose, apnoic, and cyanotic. She was resuscitated and mechanically ventilated. Organic acid analysis of a urine sample obtained $1 \mathrm{wk}$ earlier showed raised levels $(\mathrm{mol} / \mathrm{mol}$ creatinine) of lactate $(0.15$; normal up to 0.10$)$, 3-hydroxyisovalerate $(0.58), 3-\mathrm{OH}$-propionate $(0.05$, normal up to 0.02$)$ and a trace of methylcitrate. This characteristic abnormal pattern suggested the diagnosis of multiple carboxylase deficiency and the diagnosis of biotinidase deficiency was established on the next day (Table 2). However, in view of the severe brain damage due to the prolonged apnea, no biotin supplementation was given and the child died $24 \mathrm{~h}$ later. Notably in this patient skin and hair abnormalities were never observed.

\section{MATERIALS AND METHODS}

Metabolic studies. Organic acids in urine and short chain fatty acids in plasma of patient T.A. were determined by GC/MS (8).

Biotin concentrations were determined in urine samples by a microbiologic assay using Lactobacillus plantarum-ATCC 8014 (9). Biotin and biotin- $d$-sulfoxide are measured by this method but not biocytin and other biotin derivatives. Biocytin was estimated in urine by a HPLC-method (10).

Creatinine was determined in urine samples by the Automatic Analyzer 705 (Hitachi Ltd., Tokyo, Japan) using an adapted Jaffê method.
Biotinidase activity in plasma was measured by a slight modification (11) of the colourimetric method of Knappe et al. (12).

PCC, MCC, PC activities were determined in lymphocyte homogenates as described earlier (11).

GLDH (13) activity was determined in the crude enzyme homogenates as mitochondrial control enzyme by following the disappearance of the absorbance of NADH at $340 \mathrm{~nm}$.

Postmortem Studies. Tissue samples. Samples of liver, kidney and brain (prefrontal cortex and white matter of both hemispheres) were obtained from patient T.A. Ten h postmortem for biochemical investigations. Postmortem control tissues were obtained from children without metabolic disorders. Fresh human liver samples were obtained from three adult kidney donors and fresh kidney cortex samples from two adults who underwent nephrectomy because of a tumor. Rat tissues (strain A.C.J., August Cupehagen inbreed) were used as additional controls because for obvious reasons no fresh human brain tissue was available. All the samples were frozen in dry ice and stored at $-60^{\circ} \mathrm{C}$ until assayed.

Preparation of tissue homogenates and determination of carboxylase activities. For the determination of the mitochondrial carboxylases (PCC, MCC, and PC) small pieces were cut from the frozen tissues and homogenized rapidly in $15 \mathrm{mmol} / \mathrm{L}$ Tris$\mathrm{HCl}$ buffer $\mathrm{pH} 7.8$ containing $1 \mathrm{mmol}$ DTT/L with a motorized Teflon potter homogenizer ( 8 strokes, $570 \mathrm{rpm}$ ) at room temperature. The suspension was sonicated two times for $15 \mathrm{~s}$ with a microprobe of an MSE sonicator (150 W, setting 6-low) and the carboxylase activities were assayed immediately in this homogenate.

PCC, MCC, and PC activities were assayed by measuring the enzyme-dependent incorporation of ${ }^{14} \mathrm{C}$-bicarbonate to acidnonvolatile products, as described for lymphocytes (11), except that the incubation time was decreased to 5 min and 3-methylcrotonyl-CoA concentration in MCC assay was increased to 2.15 $\mathrm{mmol} / \mathrm{L}$. In kidney and liver homogenates PCC, MCC, and PC activities were linear at least up to $5 \mathrm{~min}$ with protein concentration up to $30 \mu \mathrm{g} /$ assay (PCC, MCC) or up to $50 \mu \mathrm{g} /$ assay (PC). In brain homogenates the activities were linear at least up to 7.5 min with protein concentration up to $50 \mu \mathrm{g} /$ assay (PCC, MCC) or up to $75 \mu \mathrm{g} /$ assay (PC).

For the determination of the cytosolic ACC tissue samples were homogenized in ice cold $20 \mathrm{mmol} / \mathrm{L}$ Tris-acetate buffer $\mathrm{pH}$ 7.5 supplemented with $1 \mathrm{mmol}$ DTT/L with a motorized homogenizer, as described above. The homogenates were centrifuged at room temperature for $5 \mathrm{~min}$ in an Eppendorf centrifuge (14 $000 \mathrm{rpm})$. The supernatant was used as source of the enzyme.

ACC activity was assayed by measuring the citrate activated incorporation of ${ }^{14} \mathrm{C}$-bicarbonate into malonyl-CoA by a modification of the methods described by Majerus et al. (14) and Allred and Roehrig (15). The preincubation mixture contained in a final volume of $75 \mu \mathrm{L}: 6 \mu \mathrm{mol}$ Tris-acetate buffer $\mathrm{pH} 7.5,1$ $\mu \mathrm{mol} \mathrm{Mg}$-acetate, $0.1 \mu \mathrm{mol}$ EDTA-Na pH 7.5, $0.075 \mu \mathrm{mol}$ DTT, $0.75 \mu \mathrm{mol} \mathrm{K}$-citrate, and $25 \mu \mathrm{L}$ of the crude enzyme homogenate (corresponding to $0.1-0.3 \mathrm{mg}$ protein). After $75 \mathrm{~min}$ at $30^{\circ} \mathrm{C}$ the assay tubes were placed in ice (ACC activity remained stable for at least $1.5 \mathrm{~h}$ ). To measure ACC activity the tubes were warmed to $30^{\circ} \mathrm{C}$ within $45 \mathrm{~s}$. Then $10 \mu \mathrm{L}$ of a solution containing 20 $\mathrm{mmol} / \mathrm{L}$ neutralized ATP and $14.2 \mathrm{mmol} / \mathrm{L}$ acetyl-CoA were added and the reaction was immediately started by adding 15 $\mu \mathrm{L}$ of $200 \mathrm{mmol} / \mathrm{L} \mathrm{NaH}^{14} \mathrm{CO}_{3}$ (sp act $1.7 \mathrm{mCi} / \mathrm{mmol}$ ). Each assay was performed in triplicate and for each enzyme homogenate two blanks were prepared in which acetyl-CoA was omitted. The reaction was stopped after $60 \mathrm{~s}$ by adding $50 \mu \mathrm{L}$ of $20 \%$ trichloracetic acid. The samples were further processed as described for PCC, MCC, and PC (11). ACC activity was linear with time up to $75 \mathrm{~s}$ with protein concentrations at least up to $0.4 \mathrm{mg} /$ assay tube. Protein concentration was determined in an aliquot of the tissue homogenates after trichloroacetic acid precipitation by the Biuret method.

Neuropathology. After removal of fresh tissue for biochemical 
Table 1. Carboxylase activities in lymphocyte homogenates

\begin{tabular}{|c|c|c|c|c|}
\hline \multirow[b]{2}{*}{ Subject } & \multicolumn{3}{|c|}{ Carboxylase activities, $\mathrm{pmol} / \mathrm{min} / \mathrm{mg}$ protein } & \multirow{2}{*}{$\frac{\begin{array}{c}\mathrm{nmol} / \mathrm{min} / \mathrm{mg} \\
\text { protein }\end{array}}{\mathrm{GLDH}}$} \\
\hline & PCC & $\mathrm{MCC}$ & $\mathrm{PC}$ & \\
\hline Patient & 73 & 43 & 5.1 & 32.1 \\
\hline Normal values & $694 \pm 86$ & $468 \pm 102$ & $69.9 \pm 16.4$ & $34.9 \pm 7.1$ \\
\hline Mean $\pm \mathrm{SD}$ (range) $(n=34)$ & $(492-811)$ & $(288-681)$ & $(44.4-119)$ & $(21.5-48.6)$ \\
\hline
\end{tabular}

studies, the brain was fixed in $10 \%$ neutral buffered formalin and examined grossly. The spinal cord was not available for examination. Tissue blocks from several regions of the brain were embedded in paraffin and routinely processed for neuropathologic examinations.

\section{RESULTS}

Metabolic Studies. The only abnormality in organic acid pattern in two urine samples obtained at the age of 15 mo was a slight increase in 3-hydroxy-isovalerate and lactate excretion, i.e. a rather unspecific finding. Biotinidase deficiency was suggested only when a third urine sample, obtained shortly before death, revealed, in addition to 3-hydroxy-isovalerate and lactate, slightly elevated 3-hydroxy-propionate concentrations and a trace amount of methylcitrate, i.e. a pattern typical for multiple carboxylase deficiency. In a blood sample taken $12 \mathrm{~h}$ before death, the activities of the mitochondrial carboxylases in lymphocytes were severely reduced: $7.3 \%$ (PC), $9.2 \%(\mathrm{MCC})$, and $10.5 \%$ (PCC) of mean normal value (Table 1), confirming multiple carboxylase deficiency. Biotinidase activity was $0.6 \%$ of the mean normal value in plasma of the patient and within the heterozygous range ( 48 and $57 \%$ ) in plasma of the parents (Table 2). Biotin was undetectable in urine, but biocytin was found in a concentration similar to that of biotin in healthy subjects (Table 2).

Carboxylase Activities in Tissue Homogenates. Stability of carboxylase activities. MCC, PC, and ACC activities proved to be unstable in human postmortem tissues resulting in low and widely varying activities as compared to those in rat tissues or in fresh human liver (see control children, Tables 3-5). This instability was not due to storage of the tissues at $-60^{\circ} \mathrm{C}$ because all enzyme activities remained stable at least for $1 \mathrm{y}$ in liver, kidney, and brain of rats; in fresh human liver the activities decreased maximally to $56 \%$ after 10 mo (results not shown). The mitochondrial carboxylases in postmortem tissues of the patient and control children were assayed within $1 \mathrm{wk}$ and ACC activities within $1 \mathrm{y}$. The instability seemed neither to be due to delay in freezing the samples after death since there was no correlation between postmortem time and the enzyme activities in tissues of control children (Tables 3-5). In experiments with tissues removed from rats stored at $+4^{\circ} \mathrm{C}$ after killing, the activities of MCC and PC decreased to maximally $70 \%$ after $9 \mathrm{~h}$ and to maximally $66 \%$ after $24 \mathrm{~h}$ (not shown). Because of the instability in human postmortem tissues no conclusion can be drawn from the data of MCC, PC, and ACC activities in tissues of our patient. PCC activities (as well as those of the control enzyme GLDH), however, were stable in postmortem tissues and comparable to those in rat tissues and in fresh human liver and kidney (Tables 3-5).

PCC-activities in tissues of patient. As can be seen from Tables 3 and 4 , the PCC activities in liver and kidney of the patient were only moderately decreased, i.e. to 28 and $42 \%$, respectively, of mean value in postmortem tissues of control children. However, PCC activity in the brain tissue of the patient (frontal cerebral cortex) was severely decreased, i.e. to $3.1 \%$ of the mean value in control children (Table 5). Comparable results were obtained when the activities were calculated per mg protein and per $\mu \mathrm{g}$ DNA (results not shown). Inasmuch as the activity of the mitochondrial control enzyme GLDH was normal in brain of
Table 2. Biotinidase activities ( $\mathrm{nmol} / \mathrm{min} / \mathrm{mL}$ ) in plasma, and biocytin and/or biotin concentrations in urine (nmol/mmol creatinine)

\begin{tabular}{lccc}
\multicolumn{1}{c}{ Subject } & $\begin{array}{c}\text { PLASMA } \\
\text { biotinidase activity }\end{array}$ & $\begin{array}{c}\text { URINE } \\
\text { biotin }\end{array}$ & Biocytin \\
\hline Patient & 0.035 & ND* & 18.8 \\
Mother & 2.78 & 6.64 & - \\
Father & 3.32 & - & - \\
Normal values & $5.78 \pm 1.02$ & 15.8 & $<0.4$ \\
Mean \pm SD (range) & $(4.01-7.98)$ & $(1.8-50.1)$ & \\
& $n=74$ & $n=12$ & \\
\hline
\end{tabular}

\section{* Not detectable.}

the patient, and because clearly measurable activities of $\mathrm{MCC}$, $\mathrm{PC}$, and ACC were obtained in her liver and kidney, we consider that the tissue samples of the patient were in a good state of preservation (brain sampled and stored under similar conditions as liver and kidney).

Neuropathologic Observations. The 21.5-mo-old infant weighed $10.5 \mathrm{~kg}$ at autopsy. The pertinent findings were related to the CNS. The brain weighed $900 \mathrm{~g}$ in the fresh state and was symmetric and of normal consistency. Coronal sections of the cerebral hemispheres and transverse sections of the brainstem after formaldehyde fixation disclosed several roughly symmetrical areas of softening and discoloration in the posterior part of the corpus callosum, fornix, periventricular parts of thalamic nuclei, mamillary bodies, and the periaqueductal gray matter. Foci of brownish red discoloration were found in the central part of both optic nerves (Fig. $1 A-D$ ).

Microscopic examination of the brain revealed additional small spongy lesions in the subcortical white matter of cerebral hemispheres, tectum, and tegmentum of the midbrain, substantia nigra, midline and oculomotor nuclei, tegmentum of the pons, dorsomedial parts of the medulla oblongata, and in the deeper parts of the cerebellar white matter involving the cerebellar nuclei.

The histology of the lesions was characterized by rarefaction and sponginess of the neuropil with occasional microcysts, apparent increase in the number of small blood vessels with enlargement of their endothelial cells, fibrillary astrocytosis, loss of oligodendrocytic nuclei, loss of myelin sheaths, and slight phagocyte formation (Fig. 2). Axons and nerve cell bodies were involved to a lesser degree than other structures. However, the number of axons was severely decreased in the central part of the optic nerves and there were almost no neurons left in the mamillary bodies. Conventional histology of the sural nerve disclosed no abnormality. Skeletal muscles were not examined.

\section{DISCUSSION}

Clinical course. Our patient received some free biotin with her diet up to the age of $9 \mathrm{mo}$. At $11 \mathrm{mo}$ respiratory symptoms developed and thereafter stridor dominated the clinical presentation. Neurologic symptoms appeared only gradually. Typical symptoms of biotinidase deficiency, such as skin or hair abnormalities were absent. Metabolic screening revealed slightly elevated levels of lactate and alanine and borderline normal results for organic acids at 15 mo when severe neurologic deterioration 
Table 3. Carboxylase activities in liver homogenates

\begin{tabular}{|c|c|c|c|c|c|c|}
\hline \multirow[b]{2}{*}{ Subject, age } & \multirow[b]{2}{*}{ H postmortem* } & \multicolumn{5}{|c|}{ Enzyme activities, $\mathrm{nmol} / \mathrm{min} / \mathrm{mg}$ protein } \\
\hline & & GLDH & $\mathrm{PCC}$ & $\mathrm{MCC}$ & $\mathrm{PC}$ & $\mathrm{ACC}$ \\
\hline Patient: 1 y 9 mo & 10 & 440 & 5.27 & 0.72 & 5.65 & 0.62 \\
\hline \multicolumn{7}{|l|}{ Control tissues } \\
\hline \multicolumn{7}{|l|}{ Postmortem tissues } \\
\hline Child A, 1 y 3 mo & 5 & 400 & 17.4 & 0.24 & - & 0.62 \\
\hline Child B, 5 mo & 7.5 & 530 & 23.8 & 3.23 & 15.5 & 1.87 \\
\hline Child C, 2 y 7 mo & 11.5 & 490 & 19.7 & 2.51 & 0.77 & 0.96 \\
\hline Child $\mathrm{D}, 5$ y $5 \mathrm{mo}$ & 22 & 360 & 14.2 & 1.21 & 1.78 & 1.08 \\
\hline Child E, $27 \mathrm{~d}$ & 27 & 322 & 14.0 & 2.28 & 12.7 & 1.53 \\
\hline \multirow[t]{3}{*}{ Child F, 2 mo } & 34 & 360 & 22.2 & $\underline{0.02}$ & - & $\underline{1.03}$ \\
\hline & Mean & $\overline{437}$ & $\overline{18.5}$ & $\overline{1.58}$ & 7.69 & $\overline{1.18}$ \\
\hline & $\mathrm{cv}(\%)$ & $20 \%$ & $22 \%$ & $82 \%$ & $98 \%$ & $38 \%$ \\
\hline \multicolumn{7}{|l|}{ Fresh human liver } \\
\hline 3 adult men & "0" & $470-520$ & $10.2-19.7$ & $2.04-2.67$ & $19.9-27.7$ & $2.06-3.24$ \\
\hline \multicolumn{7}{|l|}{ Fresh rat liver } \\
\hline 3 adult rats & "0" & $234-270$ & $17.0-18.3$ & $5.24-5.33$ & $28.9-35.2$ & $4.96-6.76$ \\
\hline
\end{tabular}

* Time of autopsy (h after death); tissue samples immediately frozen at $-60^{\circ} \mathrm{C}$.

Table 4. Carboxylase activities in kidney cortex homogenates

\begin{tabular}{|c|c|c|c|c|c|c|}
\hline \multirow[b]{2}{*}{ Subject, age } & \multirow[b]{2}{*}{ H postmortem* } & \multicolumn{5}{|c|}{ Enzyme activities, $\mathrm{nmol} / \mathrm{min} / \mathrm{mg}$ protein } \\
\hline & & GLDH & $\mathrm{PCC}$ & $\mathrm{MCC}$ & $\mathrm{PC}$ & $\mathrm{ACC}$ \\
\hline Patient: 1 y 9 mo & 10 & 180 & 10.3 & 0.89 & 5.11 & 0.38 \\
\hline \multicolumn{7}{|l|}{ Control tissues } \\
\hline \multicolumn{7}{|l|}{ Postmortem tissues } \\
\hline Child C, 2 y $7 \mathrm{mo}$ & 11.5 & 120 & 22.8 & 0.55 & 0.02 & 0.67 \\
\hline Child E, $27 \mathrm{~d}$ & 27 & 94 & 11.0 & 0.13 & 0.02 & 0.50 \\
\hline Child F, 2 mo & 34 & 200 & 40.3 & 3.46 & 1.32 & 1.48 \\
\hline \multicolumn{7}{|l|}{ Fresh human kidney } \\
\hline 2 adult men & “0” & 171,342 & $21.5,30.6$ & $3.54,5.61$ & $17.7,26.3$ & - \\
\hline \multicolumn{7}{|c|}{ Fresh rat kidney cortex } \\
\hline 3 adult rats & “0” & $98-108$ & $20.4-22.5$ & $9.6-11.5$ & $46.9-52.7$ & $3.11-4.94$ \\
\hline
\end{tabular}

* Time of autopsy (h after death); tissue samples immediately frozen at $-60^{\circ} \mathrm{C}$.

Table 5. Carboxylase activities in brain (cerebral cortex) homogenates

\begin{tabular}{|c|c|c|c|c|c|c|}
\hline \multirow[b]{2}{*}{ Subject, age } & \multirow[b]{2}{*}{ H postmortem* } & \multicolumn{5}{|c|}{ Enzyme activities, $\mathrm{nmol} / \mathrm{min} / \mathrm{mg}$ protein } \\
\hline & & GLDH & $\mathrm{PCC}$ & $\mathrm{MCC}$ & $\mathrm{PC}$ & $\mathrm{ACC}$ \\
\hline Patient: 1 y 9 mo & 10 & 220 & 0.18 & 0.02 & 0.03 & 0.1 \\
\hline \multicolumn{7}{|l|}{ Control tissues } \\
\hline Child C, 2 y 7 mo & 11.5 & 250 & 6.18 & 0.01 & 0.04 & 0.06 \\
\hline Child E, $27 \mathrm{~d}$ & 27 & 110 & 3.96 & 0.02 & 0.07 & 0.08 \\
\hline Child F, 2 mo & 34 & 170 & 7.23 & 0.86 & 1.64 & 0.48 \\
\hline \multicolumn{7}{|l|}{ Fresh rat brain } \\
\hline 3 adult rats & “0” & $66-83$ & $3.81-4.39$ & $1.42-1.66$ & $9.73-10.5$ & $0.91-1.42$ \\
\hline
\end{tabular}

* Time of autopsy (h after death); tissue samples immediately frozen at $-60^{\circ} \mathrm{C}$.

was evident. This atypical clinical course delayed the correct diagnosis for several months when, upon reevaluation, characteristic organic aciduria was finally found, unfortunately too late for biotin supplementation.

Respiratory abnormalities have only recently been described in biotinidase deficiency $(5,17,18)$. The present observation as well as those of Dionisi-Vici et al. (19) and King (20) indicate that respiratory problems, particularly laryngeal stridor, may be the first manifestation of the disease.

The symptomatology observed in our patient closely resembles that described in Leigh's disease $(21,22)$ : remitting course with acute exacerbations of respiratory difficulty, ataxia, or involun- 

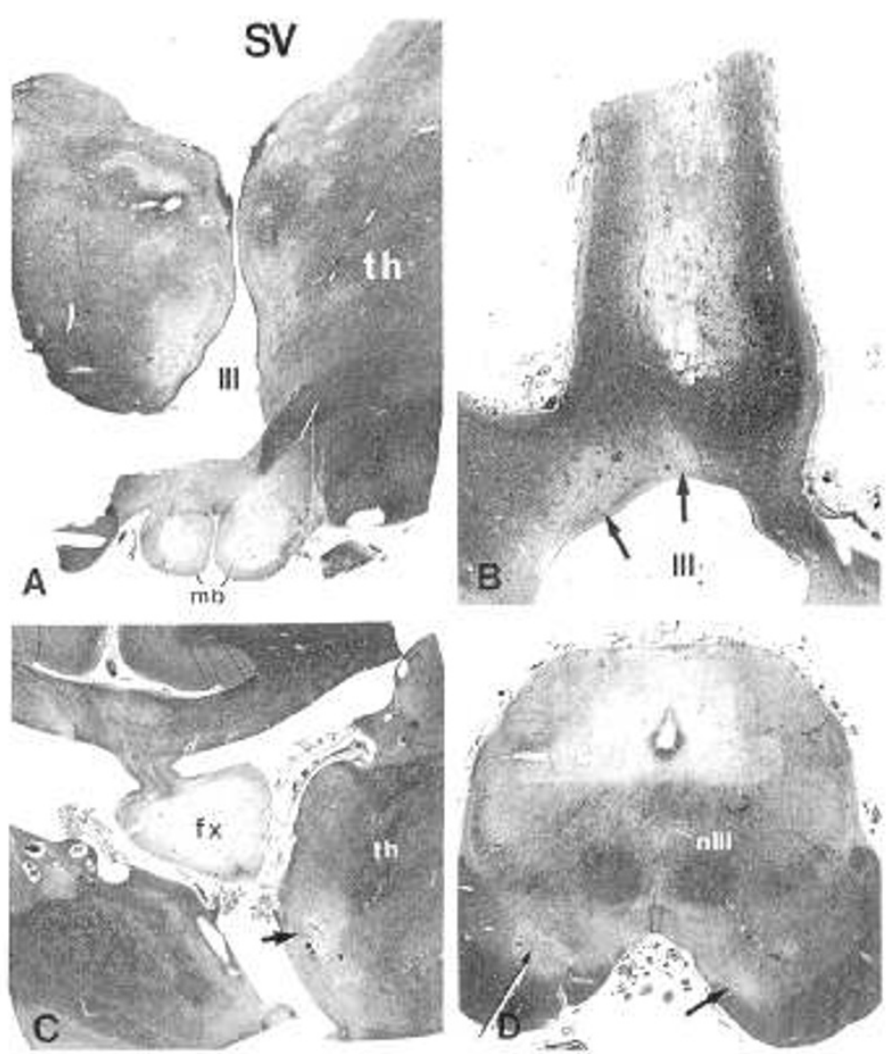

Fig. 1. $A$, thalamic nuclei $(t h)$ and mamillary bodies $(m b)$ showing roughly symmetrical, well delimited zones of spongy degeneration. In the thalamus these foci were adjacent to the third $(I I I)$ and side ventricles $(S V)$. B, right optic nerve cut longitudinally showing extensive central degeneration with loss of myelinated axons, formation of microcysts, and proliferation of microvessels. Irregular areas of pallor are also found in the wall of the third ventricle (III) (arrows). $C$, coronal sections through the corpus callosum and thalamus $(t h)$. Extensive, microcystic degeneration is found in the fornix $(f x)$. An ill-defined zone of pallor is seen also in the thalamus $(t h)$ on one side (arrow). $D$, midbrain showing almost symmetrical area of microcystic degeneration of the periaqueductal gray matter and the adjacent midbrain tegmentum and tectum. Microcystic degeneration of the oculomotor nuclei $(n I I I)$. Well delimited lesions in the substantia nigra on both sides (arrows). (Luxol-Van Gieson, $A, \times 3$; $B, \times 11 ; C, \times 3 ; D, \times 2$.)

tary movements and paralysis of cranial nerves, in our patient the vagal nerve (vocal chord paralysis). Death is usually due to respiratory failure, as in our patient.

Clinicopathologic correlation. Pathologic examination in our patient revealed SNE; Leigh's disease $(23,24)$. Leigh's disease is a degenerative condition of the CNS associated with various biochemical defects and with considerable clinical variability. Definitive diagnosis can only be made on postmortem examination of the CNS. So far only a few cases of biotinidase deficiency with histopathologic examination of the brain have been reported; none of these cases showed the classical histopathology of SNE. Chronic cerebellar degeneration and subacute myelopathy, but not encephalopathy, were documented by Sander et al. (25) in one case. Defective myelination, focal areas of vacuolation and gliosis of cerebral and cerebellar white matter have been described in another child (26). In both these cases, however, the histopathologic interpretation was complicated by additional features such as acute meningoencephalitis (25) or probably viral encephalitis (26). In a third case, a sudden infant death, biotinidase deficiency was diagnosed postmortem and focal atrophy of the cerebellar vermis was mentioned as the only pathologic finding (7).

The topography and morphology of the CNS-lesions in our

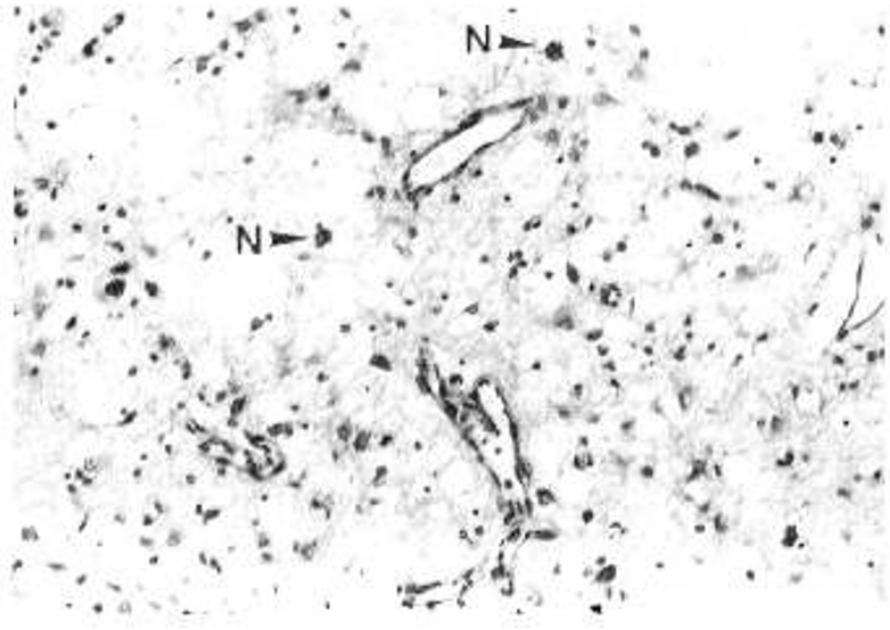

Fig. 2. High power view of midbrain periaqueductal gray matter: spongy degeneration of nervous tissue with prominent vessels and astrocytosis. Note some well preserved neurons $(N)$. (Cresyl violet, $\times 175)$.

patient were characteristic of SNE. Of particular interest was the severe involvement of white matter in the posterior part of the corpus callosum and in the fornix. Although white matter changes have been reported in SNE, their incidence seems to be low (22) and less extensive than in our case. The mamillary bodies were also severely involved in our patient. Although sparing of these nuclei in SNE is a criterium often used to distinguish SNE from Wernicke's encephalopathy, Monpetit et al. (24) reported involvement of the mamillary bodies in seven of 44 cases with SNE. However, the substantia nigra was involved in our patient, a feature not recorded in Wernicke's encephalopathy.

The clinical symptoms exhibited by our patient are in accordance with the pathologic changes observed in her brain. Respiratory difficulty with inspiratory and expiratory stridor caused by paradoxical movements of the vocal chords fits well with the extensive lesions in the medulla oblongata, involving the vagal nuclei. Central neurogenic hyperventilation as well as terminal hypoventilation and apnea might be explained by the damage observed in the brainstem tegmentum, particularly at the midbrain level (27). However, cerebral acidosis caused by the decreased carboxylase activities might have been a contributory factor.

Ataxia, a major symptom in biotinidase deficiency (5), was prominent in our patient; it was possibly related to the lesions of the cerebellar white matter, mainly in the area of the deep cerebellar nuclei, as well as to the brain stem lesions.

The severe histopathologic changes in the optic nerves with central spongy degeneration and loss of myelinated axons are consistent with the prolonged latencies of visually evoked potentials in our patient. Similar lesions may underly the visual disturbances frequently observed in patients with biotinidase deficiency, in whom institution of biotin supplementation was delayed (5). In view of the severe structural changes of the brain found in our patient it is not surprising that permanent damage to the auditory and visual pathways may occur in such cases $(6,28-30)$.

Etiology and pathogenesis. In our patient, biotinidase deficiency resulted in biotin depletion that was reflected in multiple carboxylase deficiency: in peripheral lymphocytes obtained before death the activities of PCC, MCC, and PC were reduced, each to approximately $10 \%$ of control values (Table 1). Our study indicates that $\mathrm{PCC}$ is the only stable carboxylase in human postmortem tissues, whereas PC, MCC, and ACC are unstable (Tables 3, 4, and 5). In our patient, PCC activity was severely reduced in the brain (3\% of normal), but only moderately decreased in kidney (42\%) and liver (29\%). This correlates well 
with the predominance of neurologic symptoms and the absence of major peripheral metabolic disturbances. From the results obtained in lymphocytes we assume that in the CNS the activity of MCC and PC was as severely impaired as that of PCC. As in biotinidase deficiency recycling of biotin from degraded carboxylases, including the CNS carboxylases, is not possible (40), the brain depends entirely on the supply of biotin across the bloodbrain barrier. Inasmuch as the CSF/plasma ratio of biotin in humans is around $0.22(41)$, severe systemic depletion of biotin will result in concomitant but more severe biotin deficiency of the brain. Therefore biotinylation of the apocarboxylases is expected to be impaired earlier and more severely in the CNS than in other tissues as documented in our patient. In addition, any free biotin from the diet will hardly be available to the CNS because it is likely to be captured avidly by the liver and used for biotinylation of its own apocarboxylase. These mechanisms explain why neurological symptoms are frequently the first manifestation of this disease, while organic aciduria and metabolic acidosis appear relatively late or not at all (5). This is also in accordance with the clinical observation of patients with increased CSF lactate concentrations but normal or only slightly elevated blood lactate $(17,38,39)$.

In holocarboxylase synthetase deficiency, the other known inborn error of biotin metabolism (2), as well as in acquired biotin deficiency, recycling of biotin is intact and hence the brain is less dependent on exogenous biotin supply. Obviously the pathogenesis of these two disorders must be different from that of biotinidase deficiency. Indeed, in holocarboxylase synthetase deficiency neurologic symptoms are not prominent and usually occur concomitantly with acute systemic metabolic decompensation. This is in accordance with the finding that in experimental biotin deficiency in the rat biotin concentrations (42) and carboxylase (43) were better preserved in the CNS than in the liver.

The pathogenic mechanisms resulting in the specific neuropathologic lesions of SNE are not yet understood. Several inborn errors of metabolism have been implicated, such as defects of the pyruvate dehydrogenase complex, defects of pyruvate carboxylase and cytochrome $\mathrm{C}$ oxidase, as recently reviewed by diMauro et al. (31). Other defects of the respiratory chain (affecting PDH function indirectly) may also be associated with $\mathrm{SNE}$, e.g. NADH dehydrogenase $(32,33)$ or a presumptive defect of the oxidative phosphorylation (NADH dehydrogenase ATPADP translocator or $F_{1}$-ATP-ase) (34). Our observation shows that biotinidase deficiency has to be added to this list. All these defects play an essential role in energy metabolism and may account for metabolic acidosis and increased pyruvate and lactate levels in physiologic fluids and tissues, including the brain and CSF.

The common factor in the pathogenesis of SNE thus appears to be related to lactate/pyruvate metabolism. Increased lactate concentration in the CSF has often been documented in SNE (32). Different neuropathologic changes have been described in other organic acidemias, such as propionic- and methylmalonic acidemia or maple syrup urine disease.

From our findings and observations in the literature we speculate that chronic lactate accumulation in the brain and/or factors involved in pyruvate metabolism (such as pyruvate, abnormalities of NAD/NADH ratio and intracellular compartmentation) play an important role in the pathogenesis of the specific neuropathologic lesions seen in SNE, irrespective of the basic underlying defect. This hypothesis is supported by the close histopathologic resemblance of SNE and Wernicke's encephalopathy (24). In Wernicke's encephalopathy thiamine deficiency interferes with the normal function of pyruvate dehydrogenase complex. In addition, lactate has been shown to be toxic to the brain (35) and seems to be involved in neovascularization (36). Possibly lactate provokes the characteristic proliferation of endothelial cells in SNE and Wernicke's encephalopathy. The specific and symmetrical distribution of the CNS lesions in the diencephalon and brainstem points to a selective local susceptibility of these structures or to metabolite accumulation, perhaps due to regional differences of certain enzyme activities connected with pyruvate metabolism (37). However, additional factors may be involved because several patients with documented biochemical abnormality in pyruvate metabolism and/or raised CSF lactate had neuropathologic abnormalities distinct from Leigh syndrome (SNE).

Acknowledgments. We thank Dr. Alison Feess-Higgins for help in preparing the manuscript. We are indebted to Ms. J. Engler and her group (Department of Vitamin and Nutrition Research, F. Hoffman-La Roche \& Co., Ltd., Basel, Switzerland) for the biotin determinations.

\section{REFERENCES}

1. Wolf B, Grier RE, Parker WD, Goodman SI, Allen RJ 1983 Deficient biotinidase activity in late-onset multiple carboxylase deficiency. $\mathrm{N}$ Engl $\mathrm{J}$ Med 308:161

2. Nyhan WL 1988 Minireview: multiple carboxylase deficiency. Int J Biochem 20:363 370

3. Wolf B, Grier RE, Secor McVoy JR, Heard GS 1985 Biotinidase deficiency: a novel vitamin recycling defect. J Inherit Metab Dis 8(suppl 1):53-58

4. Baumgartner ER, Suormala TM, Wick H, Bausch J, Bonjour JP 1985 Biotinidase deficiency: Factors responsible for the increased biotin requirement. J Inherited Metab Dis 8(suppl 1):59-64

5. Wolf B, Heard GS, Weissbecker KA, Secor McVoy JR, Grier RE, Leshner RT 1985 Biotinidase deficiency: initial clinical features and rapid diagnosis. Ann Neurol 18:614-617

6. Baumgartner ER, Suormala TM, Wick H, Bausch J, Bonjour JP 1985 Biotinidase deficiency associated with renal loss of biocytin and biotin. Ann NY Acad Sci 442:272-286

7. Burton BK, Roach ES, Wolf B, Weissbecker KA 1987 Sudden death associated with biotinidase deficiency. Pediatrics 79:482-483

8. Bachmann C 1987 Diagnosis of urea cycle disorders. Enzyme 38:233-241

9. Frigg M, Brubacher G 1976 Biotin deficiency in chicks fed a wheat-based diet. Int J Vitam Nutr Res 46:314-321

10. Suormala TM, Baumgartner ER, Bausch J, Holick W, Wick H 1988 Quantitative determination of biocytin in urine of patients with biotinidase deficiency using high-performance liquid chromatography (HPLC). Clin Chim Acta $177: 253-270$

11. Suormala T, Wick H, Bonjour JP, Baumgartner ER 1985 Rapid differential diagnosis of carboxylase deficiencies and evaluation of biotin responsiveness in a single blood sample. Clin Chim Acta 145:151-162

12. Knappe J. Brümmer W, Biederbick K 1963 Reinigung und Eigenschaften der Biotinidase aus Schweinenieren und Lactobacillus casei. Biochem $\mathrm{Z}$ 338:599-613

13. Leighton F, Poole B, Beaufay H 1968 The large-scale separation of peroxisomes, mitochondria and lysosomes from the liver of rats injected with Triton WR-1339. J Cell Biol 37:482-513

14. Majerus PW, Smith MB, Clamon GH 1969 Lipid metabolism in human platelets. I. Evidence for a complete fatty acid synthesizing system. J Clin Invest 48:156-164

15. Allred JB, Roehrig KL 1980 Inhibition of rat liver acetyl CoA carboxylase chloride. J Lipid Res 21:488-491

16. Lowry OH, Rosebrough NJ, Farr AL, Randall RJ 1951 Protein measurement with the folin phenol reagent. J Biol Chem 193:265-275

17. Di Rocco M, Superti-Furga A, Durand P, Cerone R, Romano C 1984 Different organic acid patterns in urine and in cerebrospinal fluid in a patient with biotinidase deficiency. J Inherit Metab Dis 7(suppl 2):119-120

18. Mitchell G, Ogier H, Munnich A, Saudubray JM, Shirrer J, Charpentier C, Rocchiccioli F 1986 Neurological deterioration and lactic acidemia in biotinidase deficiency. A treatable condition mimicking Leigh's disease. Neuropediatrics 17:129-131

19. Dionisi-Vici C, Bachmann C, Graziani MC, Sabetta G 1988 Laryngeal stridor as a leading symptom in a biotinidase-deficient patient-case report. J Inherited Metab Dis 11:312-313

20. King M 1984 Biotin-responsive stridor etcetera, Abstracts of free communications. 22nd Annual Symposium, Society for the Study of Inborn Errors of Metabolism, p 22

21. Pincus JH 1972 Subacute necrotizing encephalomyelopathy (Leigh's disease); a consideration of clinical features and etiology. Dev Med Child Neurol 14:87-101

22. Adams RD, Lyon G 1982 Early infantile progressive metabolic encephalopathies: Clinical problems and diagnostic considerations. In: Jeffers JD, Zauber K, King SJ, eds. Neurology of Hereditary Metabolic Diseases of Children. Hemisphere Publishing Corp Washington, New York, pp 73-82

23. Leigh D 1951 Subacute necrotizing encephalomyelopathy in an infant. $J$ Neurol Neurosurg Psychiat 14:216-221

24. Montpetit VJA, Andermann F, Carpenter S, Fawcett JS, Zborowska-Sluis D, Giberson HR 1971 Subacute necrotizing encephalomyelopathy-a review and a study of two families. Brain 94:1-30

25. Sander JE, Malamud N, Cowan MJ, Packman S, Amman AJ, Wara DW 1980 
Intermittent ataxia and immunodeficiency with multiple carboxylase deficiencies: a biotin-responsive disorder. Ann Neurol 8:544-547

26. Allen RJ, Wolf B, Grier RE, Dorovini-Zis K 1983 Infantile seizures in biotinidase deficiency. Ann Neurol 14:386

27. Plum F, Posner JB 1980 Respiration. In: Contemporary Neurology Series, vol 19, 3rd ed. Diagnosis of Stupor and Coma. Davis FA Co., Philadelphia pp $32-41$

28. Taitz LS, Leonard JV, Bartlett K 1985 Long-term auditory and visual complications of biotinidase deficiency. Early Hum Dev 11:325-331

29. Greter J, Holme E, Lindstedt S, Koivikko M 1985 Biotin-responsive 3methylcrotonylglycinuria with biotinidase deficiency. $J$ Inherit Metab Dis 8(suppl 2): 103-104

30. Thuy LP, Zielinska B, Zammarchi E, Pavari E, Vierucci A, Sweetman F, Sweetman L, Nyhan WL 1986 Multiple carboxylase deficiency due to deficiency of biotinidase. J Neurogenet 3:357-363

31. DiMauro S, Servidei S, Zeviani M, DiRocco M, DeVivo DC, DiDonato S, Uziel G, Berry K, Hoganson G, Johnson SD, Johnson PC 1987 Cytochrome c oxidase deficiency in Leigh syndrome. Ann Neurol 22:498-506

32. Van Erven PMM, Gabreels FJM, Ruitenbeek W, Den Hartog MR, Fischer JC, Renier WO, Trijbels JMF, Sloof JL, Janssen AJM 1985 Subacute necrotizing encephalomyelopathy (Leigh syndrome) associated with disturbed oxidation of pyruvate, malate and 2-oxoglutarate in muscle and liver. Acta Neurol Scand 72:36-42

33. Van Erven PMM, Fischer JC, Gabreels FJM, Renier WO, Trijbels JMF Janssen AJM 1986 Defect of NADH dehydrogenase in Leigh syndrome.
Acta Neurol Scand 74:167

34. Van Erven PMM, Ruitenbeek W, Gabreels FJM, Renier WO 1986 Disturbed oxidative metabolism in subacute necrotizing encephalomyelopathy (Leigh syndrome). Neuropediatrics 17:28-32

35. Myers RE 1979 A unitary theory of causation of anoxic and hypoxic brain pathology. Adv Neurol 26:195-217

36. Imre G 1977 The role of lactic acid in neovascularizations. Albrecht Graefes Arch Klin Exp Ophtal 201:263-266

37. Reynolds SF, Blass JP 1976 A possible mechanism for selective cerebellar damage in partial pyruvate dehydrogenase deficiency. Neurology 26:625628

38. Diamantopoulos N, Painter MJ, Wolf B, Heard GS, Roe C 1986 Biotinidase deficiency: Accumulation of lactate in the brain and response to physiologic doses of biotin. Neurology 36:1107-1109

39. Fois A, Cioni M, Balestri G, Baumgartner ER, Bachmann C 1986 Biotinidase deficiency: metabolites in CSF. J Inherited Metab Dis 9:284-285

40. Suchy SF, Secor McVoy J, Wolf B 1985 Neurologic symptoms of biotinidase deficiency: possible explanation. Neurology 35:1510-1511

41. Baker H, Frank O, DeAngelis B, Feingold S 1983 Vitamins in human blood and cerebrospinal fluid after intramuscular administration of several Bvitamins. Nutr Rep Int 27:661-670

42. Bhagavan HN Coursin DB 1970 Depletion of biotin from brain and liver in biotin deficiency. J Neurochem 17:289-290

43. Achuta Murthy PN, Mistry SP 1977 Biotin, Prog Fd Nutri Sci 2:405-455 